\title{
UMA ANÁLISE SOCIOESPACIAL SOBRE OS AGLOMERADOS SUBNORMAIS EM GOIÂNIA-GO: FRONTEIRAS, APLICAÇÕES E DIMENSÕES
}

Lídia Milhomem Pereira ${ }^{1}$

\section{Resumo}

O objetivo deste trabalho é apresentar, explicitar, indagar e verificar de maneira incipiente, como funcionam as interações entre segregação socioespacial, mapeamento das fronteiras com os lugares considerados aglomerados subnormais localizados na capital de Goiânia e criados diante do atual sistema econômico. Através da especulação imobiliária, com a venda dos imóveis de luxo nos setores nobres da cidade, faz com que as esferas econômicas, sociais e políticas alterem a ordem de planejamento, gestão e reordenação do território em determinados bairros de Goiânia. Desse modo, o objeto espacial do presente estudo abrangerá por análise de dados recorrendo ao Índice de Moran, IDW e a criação de agrupamentos, os aglomerados subnormais em Goiânia, GO, incluindo os estudos referentes aos processos dês-territorialização-reterritorialização e criação de fronteiras.

Palavras Chave:Índice de Moran; aglomerados subnormais; Goiânia

\begin{abstract}
The objective of this paper is to present, explain, investigate and verify incipient way, how they work the interactions between socio-spatial segregation, mapping the borders of posts deemed substandard clusters located in the capital of Goiania and raised on the current economic system. Through real estate speculation, the sale of luxury properties in prime areas of the city makes the economic, social and political spheres change the order of planning, management and reorganization of theterritory in certainneighborhoods of Goiânia. Thus, the space object of this study cover for data analysis using the Moran index, IDW and the creation of clusters, the subnormal agglomerates in Goiania, GO, includingstudies of theproceedingsdes-territorialreterritorial and creationborders.
\end{abstract}

Keywords:Index of Moran; subnormal agglomerates; Goiânia

1 Programa de Pós-Graduação em Geografia do IGC/UFMG; Doutoranda; (limilhomem@gmail.com) 


\section{1- GOIÂNIA EM FOCO: BREVE CONTEXTUALIZAÇÃO}

Goiânia é um município brasileiro, capital do estado de Goiás. Pertence à Mesorregião do Centro Goiano e à Microrregião de Goiânia, distando 209 km de Brasília, a capital nacional. Com uma área de aproximadamente $739 \mathrm{~km}^{2}$, possui uma geografia contínua, com poucos morros e baixadas, tendo terras planas na maior parte de seu território, com destaque para o rio Meia Ponte.

Localizada no centro do seu estado, foi planejada e construída para ser a capital política e administrativa de Goiás sob influência da Marcha para o Oeste, política desenvolvida pelo governo Vargas para acelerar o desenvolvimento e incentivar a ocupação do Centro-Oeste brasileiro.

Sofreu um acelerado crescimento populacional desde a década de 1960, atingindo um milhão de habitantes cerca de sessenta anos depois de sua fundação. Desde seu início, a sua arquitetura teve influência do Art Déco, que definiu a fisionomia dos primeiros prédios da cidade. É a segunda cidade mais populosa do Centro-oeste, sendo superada apenas por Brasília.

Situa-se no Planalto Central e é um importante polo econômico da região, sendo considerada um centro estratégico para áreas como indústria, medicina, moda e agricultura. Contudo, tem enfrentado desafios, entre eles a desigualdade social, crescentes problemas de trânsito, índices de criminalidade elevados e o clima seco, resultado da poluição e por se localizar no cerrado brasileiro.

Entretanto, Goiânia destaca-se entre as capitais brasileiras por possuir o maior índice de área verde por habitante do Brasil, ultrapassada apenas por Edmonton em todo o mundo.(Disponível em http://www.goianiabr.com.br/2012/08/onu-revela-que-goiania-ecidade-mais.html. Acesso em julho de 2015.)

O objetivo deste trabalho é apresentar, explicitar, indagar e verificar de maneira incipiente, como funcionam as interações entre segregação socioespacial, mapeamento das fronteiras e com os lugares considerados aglomerados subnormais localizada emsetores da capital, e criados diante do atual sistema econômico. Através da especulação imobiliária, com a venda dos imóveis de luxo nos setores nobres da cidade, faz com que as esferas econômicas, sociais e políticas alterem a ordem de planejamento, gestão e re-ordenação do território em determinados bairros de Goiânia.

Segundo Pela(2014, p.32), defende-se que as edificações de Goiânia, Brasília e Palmas estão intrinsecamente relacionadas com a transformação, em um tempo histórico curto e denso, do bioma Cerrado em território, uma vez que a ideologização em torno das cidades planejadas foi 
mais uma das estratégias de poder para formar a massa urbana necessária para concretizar o projeto de "modernização" e urbanização do território brasileiro, conter as revoltas da classe trabalhadora tanto do sudeste como do centro-oeste, possibilitar o controle socioterritorial do Estado sobre esta classe trabalhadora e garantir a substituição, em um primeiro momento, da oligarquia rural-agrária para a urbano-industrial.

Ainda para esta autora, as localizações destas cidades-capitais fazem parte das estratégias de consolidação do projeto do Brasil integrado que, como já apontado, inicia-se em 1930.É salutar explicar que, fruto do processo de industrialização, irá criar certa "homogeneidade" do mercado e do espaço nacional, desenvolvimentista e integracionista do governo de Getúlio Vargas. No entanto, vale indagar: o que realmente foi integrado e a quem favorece este projeto de integração? Para responder a esta indagação, a autora amparou-se nas considerações de Oliveira F. (2003p.20), que versam sobre as causas e consequências deste processo, e de Raffestin (1980), que falam sobre as estratégias geográficas do poder.

Para Oliveira F. (2003p.24), a década de 1930 é o marco da inserção e da filiação da economia brasileira ao sistema capitalista. As causas externas deste processo são, principalmente, o vazio criado pela crise do sistema capitalista nesta época - aprofundado mais tarde com a Segunda Guerra Mundial - e a nova divisão internacional do trabalho que restaurará aos países não industrializados, caso do Brasil, a condição de produtor de matérias-primas e produtos agrícolas para abastecimento do mercado externo. No entanto, para isso acontecer seriam necessárias algumas transformações nas estruturas política, econômica e socioespacial internas do país, tais como:

a. A readequação das estruturas políticas internas que culminará em uma "troca" de poder entre as classes de proprietários rurais e a nova burguesia empresário-industrial;

b. A instauração de um novo modelo econômico, ou seja, de agrário-rural o Brasil deveria tornar-se urbano-industrial;

c. A mudança, gradual, do modo de acumulação primária para integral;

d. O deslocamento das correntes migratórias e das fronteiras agrícolas e econômicas do país para a região Centro-Oeste-Norte;

Em outras palavras, estavam anunciados os caminhos da nova geopolítica do país que, necessariamente, deveria transformar as terras da porção centro-oeste-norte do país, até então. É 
importante ressaltar que tanto Brasília como Palmas fazem parte do antigo território goiano e, segundo Machado (2007, p.52):

...Foram, então, os viajantes estrangeiros que criaram a imagem do 'GoiásSertão' ao se depararem com uma província em crise após a queda da produção do ouro. Viram apenas um deserto de homens, uma região sem comércio e perspectiva. Os seus olhares acostumados aos padrões da modernidade e progresso, às sociedades em industrialização da Europa, viam em Goiás a imagem do sertão, até mesmo pela enorme distância do litoral. [...] O que se pode afirmar é que essa imagem é quase sempre negativa. O sertão é uma região onde a liberdade é irrestrita, sem sujeição a nenhuma lei, inspirando temor e perigo. Para o senso comum, o sertão não é um espaço habitável normal, caracterizando-se como um espaço incivilizado.

Cabe, todavia, advertir, conforme explica Oliveira F. (2003, p.35), que o desenvolvimento do modo de produção capitalista no Brasil tem suas particularidades que o diferenciam do desenvolvimento clássico. A principal é que haverá, em um primeiro momento, modos de acumulação distintos entre os setores primários, secundários e terciários, que não destruíram completamente a estrutura anterior. Por isto é que se encontram traços do escravismo, tanto nas relações de trabalho no campo como nas relações com os trabalhadores da construção civil, principalmente os que edificaram as cidades de Goiânia e Brasília. (Pelá, 2014, p.35).

Abaixo mapa de Goiânia seguindo a malha de setores censitários. Segundo o IBGE, a definição de setores censitários é a unidade territorial estabelecida para fins de controle cadastral, formado por área contínua, situada em um único quadro urbano ou rural, com dimensão e número de domicílios que permitam o levantamento por um recenseador. Assim sendo, cada recenseador procederá à coleta de informações tendo como meta a cobertura do setor censitário que lhe é designado. 


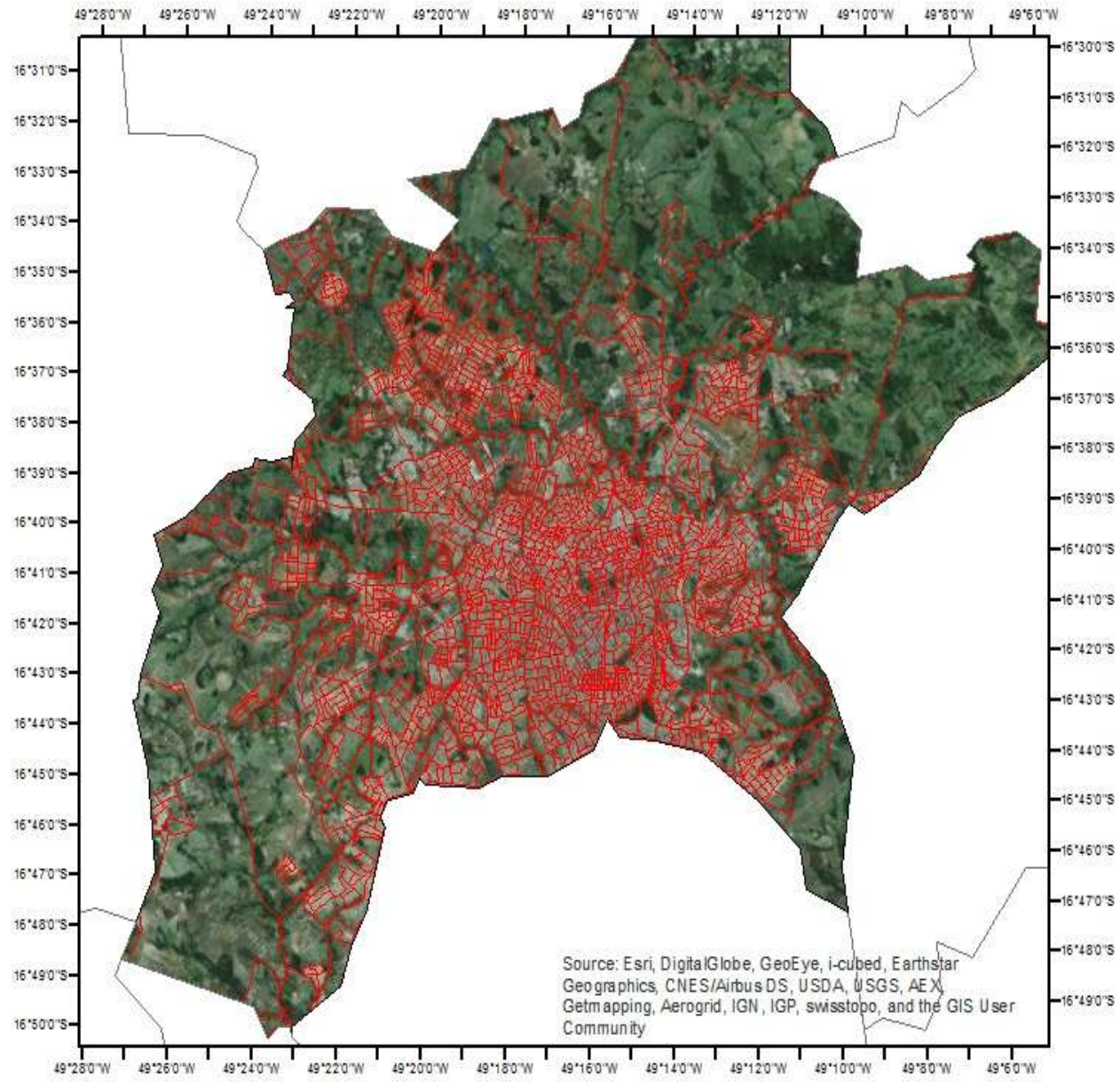

Municipio de Goiânia: 2010

Malha de setores censitários

\section{Convenções Cartográficas}
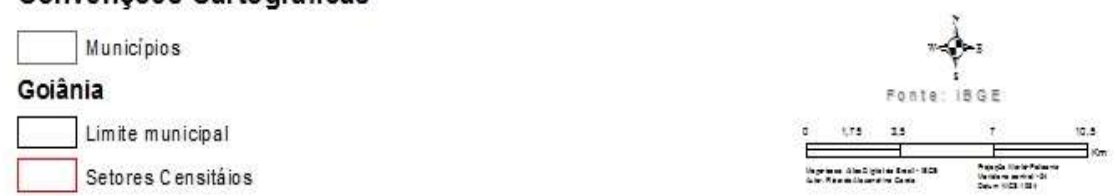

\section{2- UM PASSEIO PELA CATEGORIA CIDADE...}

A cidade é objeto da produção de imagens e discursos que se colocam no lugar da materialidade e do social que os representam. Assim, a cidade é um fenômeno que se revela pela percepção de emoções e sentimentos dados pelo viver urbano e também pela expressão de utopias, de esperanças, de desejos e medos, individuais e coletivos, que esse habitar em proximidade propicia. É, sobretudo, essa dimensão da sensibilidade que cabe recuperar para os efeitos da emergência de uma história cultural urbana: trata-se de buscar essa cidade que é fruto do pensamento, como uma cidade sensível e uma cidade pensada, urbes que são capazes de se 
apresentarem mais "reais" à percepção de seus habitantes e passantes, do que o tal referente urbano na sua materialidade e em seu tecido social concreto. (Pesavento, 2007, p.33)

Entre os autores que se dedicaram a refletir sobre a cidade, Lefebvre abriu um fecundo caminho de discussão em várias obras. Para ele, a cidade é uma força produtiva por permitir a reunião dos trabalhadores e das obras, dos conhecimentos e das técnicas, dos meios de produção, intervindo ativamente no crescimento e no desenvolvimento. A cidade se torna, no curso da história, o lugar privilegiado onde se elaboram as relações de produção, onde se manifestam os conflitos entre as relações de produção e as forças produtivas (Lefebvre, 1999, p.23).

Bresciani (2009, p.56), diz que grandes desafios devem ser avaliados, como por exemplo, as áreas degradadas da região central e as favelas da capital paulista. São Paulo e Campinas, no encarte do jornal, formam a maior malha urbana do hemisfério sul, com 27 milhões de habitantes, $12 \%$ do país, responsáveis por $65,7 \%$ do PIB do Estado e $22 \%$ do PIB brasileiro. No artigo, São Paulo aparece como uma metrópole desmedida, com um número de veículos bem maior do que a sua capacidade e já com uma situação de caos e de colapso presentes. A partir desse encarte, a historiadora descobriu muitas semelhanças de tratamento com o que tinha estudado no século XIX em Londres, com territórios de pobreza e suas características.

Silva(1997, p.22), afirma que nos países da periferia, a herança pré-capitalista é muito pesada e resistente. Os processos de racionalização (intelectualização, autonomização das esferas de valor, desmagificação) são limitados ou subvertidos. O mercado, o capital, o trabalho assalariado e a ciência são forçadas a conviver com formas de sociabilidade e dominação baseadas em personalismo, religiosidade e tradição-bastante resistentes.

Ainda para este autor, no livro "A construção de Brasília modernidade e periferia":

Tanto no seu aspecto socioeconômico (a modernização) quanto na sua dimensão cultural (o modernismo), a condição moderna na periferia tende a ser grosseira, devedora do modelo que toma e ao mesmo tempo lhe é imposto. Nessas condições, uma ideologia do moderno (o discurso dos setores dominantes que tende a legitimar a ordem capitalista erigindo a condição moderna em valor em si, capaz de auto conferir-se positividade, principalmente por meio de seu grande símbolo, a razão) assume importância capital, (SILVA,1997: p.22)

Desse modo, o objeto espacial do presente estudo abrangerá por análise de dados

recorrendo ao İndice de Moran, IDW e a criação de agrupamentos, os aglomerados subnormais em Goiânia, GO, incluindo os estudos referentes aos processos dês-territorialização-reterritorialização e criação de fronteiras. 


\section{3- O TEMA NA BIBLIOGRAFIA}

Discutir cidade, planejamento, criação de fronteiras, territorialidades, relação medomodernidade, suas implicações no espaço, poder, contextualizando com as realidades dialéticas no contexto do capitalismo farão parte deste estudo.

Constituirão como fontes citadas nesta temática os seguintes autores que relacionam a geografia urbana/cultural: Arrais, Almeida,Branco, Bresciani, Borges, Cavalcanti, Castells, Costa, Chaveiro,Claval, Garcia, Harvey, Haesbaert, Lago, Lefebvre, Santos, Silva, Oliveira, Pesavento, Simmel, Tuan, dentre outros citados na bibliografia. Com relação a Geografia estatística apoiouse na obra de MINGOTI, S.A. Análise de dados através de métodos de estatística multivariada. Belo Horizonte, Universidade Federal de Minas Gerais, 2007. Dentre outras citadas nas referências bibliográficas.

Martins (1975) afirma que "o funcionamento de mercado é que passa a ser o regulador da riqueza e da pobreza". Verifica-se que a partir do momento em que surgiu a propriedade privada da terra as relações sociais foram transformadas, de forma que a vida econômica encontrou-se estruturada pelas relações de mercado.

A relação desses grupos, minorias e inclusão vão ao encontro do que Haesbaert denominou de território. Para Haesbaert, o conceito de território há diferentes enfoques, elaborando uma classificação em que se verificam três vertentes básicas:

1) jurídico-política, segundo a qual "o território é visto como um espaço delimitado e controlado sobre o qual se exerce um determinado poder, especialmente o de caráter estatal";

2) cultural (ista), que "prioriza dimensões simbólicas e mais subjetivas, o território visto fundamentalmente como produto da apropriação feita através do imaginário e/ou identidade social sobre o espaço";

3) econômica, "que destaca a desterritorialização em sua perspectiva material, como produto espacial do embate entre classes sociais e da relação capital-trabalho". (Haesbaert, 2004). Portanto, o autor se concentra em compreender as implicações para os grupos.

Ainda para Haesbaert $(2004,2008)$ há importância da multiterritorialidade para compreender as formas de identidade e territorialização na sociedade contemporânea. Segundo o autor, nossos territórios são construídos hoje mais no movimento e na descontinuidade do que na fixação e na continuidade. Além disso, estamos constantemente envolvidos em várias territorialidades diferentes, difusas e mutantes. 


\section{4- FRAGMENTAÇÃO/SEGREGAÇÃO SOCIOESPACIAL/AGLOMERADOS}

O crescente processo da malha urbana vem acompanhado de disparidades, elementos relacionados a infraestrutura, políticas públicas e administrações habitacionais. Discutir o planejamento e as contradições no espaço urbano torna-se alvo deste trabalho.

A segregação urbana é um processo que tende a se tornar mais complexo nas grandes cidades, já que é resultante da maior amplitude da divisão sócio- espacial do trabalho no capitalismo, nessas cidades. A segregação tem a ver com disputa de territórios e com a otimização de sua apropriação, em proveito da classe dominante, "das vantagens de um espaço desigual" (Villaça, 1998, p.19).

Para Santos (2013, p.39) outro conceito que é importante para a realidade em foco é o de "fragmentação", cuja discussão é mais recente que o de segregação. Há diferentes formas de abordar a fragmentação, entre as quais se destacam: fragmentação do tecido sociopolítico-espacial (SOUZA, 2000); fragmentação espacial (SALGUEIRO, 1998); diversos tipos de fragmentação: físico material, social e político-territorial (JANOSCHKA; GLASZE, 2003);

Souza (2000, p.40) adota a fragmentação sociopolítico-espacial, tendo como primeiro plano a dimensão política, ou seja, a dimensão do poder. Assim, trata-se de fragmentação territorial, não dizendo respeito às fronteiras estatais, mas ao surgimento de poderes paralelos ao Estado, que territorializam vários pontos do espaço intra-urbano, desafiando o controle estatal. O autor cita as favelas e/ou os loteamentos nas periferias pobres das cidades, dominadas por grupos de traficantes que impõem regras de convivência aos outros moradores e aos estabelecimentos comerciais e de serviços.

A outra ponta do espectro da fragmentação do tecido sociopolítico-espacial refere-se à territorialização dos ricos, com regras previamente determinadas e mesmo legitimadas perante o Estado. O que Souza (2000, p.50) chama de "escapismo das elites para as periferias das cidades". Essa fragmentaçãose caracteriza pela dispersão das áreas residenciais das elites, em loteamentos fechados, condomínios horizontais e shopping centers, com rígidas regras de convivência e conduta (Santos, 2013, p.41).

Conforme Lefebvre (2009, p.45), o habitat tipo pavilhão proliferou ao redor de Paris, nas Comunas suburbanas, ampliando de maneira desordenada o setor construído. Única lei deste crescimento ao mesmo tempo urbano e não urbano: a especulação sobre os terrenos. Os interstícios deixados por este crescimento sem vazios foram preenchidos pelos grandes conjuntos. À especulação com os terrenos, mal combatida, somou-se a especulação com os apartamentos quando estes eram objeto de copropriedade. Assim continuava a entrada da

Cadernos do Leste 
moradia para a riqueza mobiliária e do solo urbano para o valor de uso, com as restrições desaparecendo.

\section{5- PROBLEMATIZAÇÃO}

O processo de formação da urbes, de modernização das cidades, de expansão das metrópoles, inchaço, atração e repulsão de áreas, lugares com relação emprego/lazer/pessoas, tornam-se parte deste estudo. O trabalho, com os objetos no espaço urbano, na criação de territorialidades opostas, segregação socioespacial, investiga um modelo presente de fronteira urbana/humana, na qual o indivíduo acaba sendo ele mesmo a fronteira.

As pessoas de menor renda, confrontados com a política voltada para as de maiores rendas, fazem parte de um processo histórico discrepante presente na realidade e na linha do tempo. Os mercados imobiliários goianos, principalmente diante do sistema imposto, reordenam o território com uma política descentralizadora de planejamento, para o crescimento sair da região central da capital.

Compreender essa realidade, vai ao encontro do que foi proposto, uma junção enquanto agente atuante da filologia. Neste evento em questão, a mídia muitas vezes é atuante, modificadora, real, porém, ao mesmo tempo pode ser uma fonte deturpadora e mascaradora de opiniões.

\section{6- QUESTÕES NORTEADORAS}

Nesse sentido como perceber os aglomerados subnormais no município de Goiânia? Quais as políticas utilizadas para desapropriação e reordenamento territorial na cidade? As alterações espaciais e sociais nos bairros da capital, foram e são pacificadoras ou repulsivas?Quais as principais motivações para a escolha do lugar onde se morar, na visão dos grupos opostos (menor e maior renda)? Como perceber as diferenças, os sentimentos de pertencimento e aversão com os lugares?Quem são os moradores destes territórios vizinhos e onde é a fronteira? Como a Geografia Estatística pode contribuir com os métodos para otimizar os estudos?

\section{7- PRESSUPOSTOS TEÓRICO-METODOLÓGICOS}

O propósito deste trabalho é articular os conceitos necessários para o processo de formação da urbes, de modernização das cidades, de expansão das metrópoles, inchaço, atração e repulsão de áreas, lugares, trabalho, com os objetos no espaço urbano, na criação de 
territorialidades opostas, segregação socioespacial. Pretende-se investigar um modelo presente de fronteira urbana/humana, na qual o indivíduo acaba sendo ele mesmo a fronteira, a separação.

Constituirão como fontes citadas nesta temática os seguintes autores: Almeida, Bresciani, Garcia, Harvey, Haesbaert, Lefebvre, Santos, Silva, Oliveira, Pesavento, Tuan, dentre outros citados na bibliografia e referenciados. Os recursos materiais e imateriais existentes no meio ambiente, nos espaços e nas paisagens são indispensáveis na dinâmica da criação. Tentar entender, explicitar, indagar e verificar como funcionam as interações entre os seres humanos e o meio ambiente é uma forma de criar e recriar, também, as paisagens construídas por estes seres. Os seres humanos podem fazer inúmeras escolhas e estas devem ser feitas objetivando a utilização dos diferentes espaços e paisagens para garantir a sobrevivência de grupos de um determinado lugar.

A metodologia consistirá na abordagem qualitativa e quantitativa. $\mathrm{Na}$ primeira há uma valoração da análise dos conteúdos. Segundo Teixeira (2001, p.24), a pesquisa qualitativa tem as seguintes características: o social é visto como um mundo de significados passíveis de investigação e a linguagem dos atores sociais e suas práticas são as matérias-primas dessa abordagem. Os significados, motivos, aspirações, atitudes, crenças e valores, expressos pela linguagem comum, são abordados pela pesquisa qualitativa.

O enfoque quantitativo para que seja realizada uma abrangente e fidedigna quantidade que representa todas as invasões e resultados da pesquisa. Desta maneira, objetivou-se aplicar a geoestatística e a análise no agrupamento de dados dos aglomerados subnormais em Goiânia, junto com a análise ao índice de Moran e IDW.

Conforme Jacob,Yong (2006, p.12), a Ponderação do Inverso das Distâncias (InverseDistanceWeighting) implementa explicitamente o pressuposto de que as coisas mais próximas entre si são mais parecidas do que as mais distantes. Para predizer um valor para algum local não medido, o IDW usará os valores amostrados à sua volta, que terão um maior peso do que os valores mais distantes, ou seja, cada ponto possui uma influência no novo ponto, que diminui na medida em que a distância aumenta, daí seu nome. Sua fórmula de cálculo é: $\sum==\mathrm{N}$ i ii Z s Z s $1000^{\wedge} \lambda$; onde: $0^{\wedge} 0 \mathrm{Z}$ s é o valor a ser predito para o local $0 \mathrm{~s}$; $\mathrm{N}$ é o número de pontos observados a serem usados ao redor do valor a ser predito; $\lambda$ são os pesos colocados para cada ponto observado a ser utilizado; 0 i Z s é o valor observado no local i s. Na medida em que a distância aumenta, o peso é reduzido por um fator de "p". di0 é a distância entre o local predito, $0 \mathrm{~s}$, e cada um dos locais observados, i s. Os pesos dos locais observados, a serem usados na predição, são ponderados, e sua soma é igual a 1. O valor "p" é determinado minimizando o 
erro médio quadrático da predição (RMSPE), que é a estatística calculada por um procedimento de validação cruzada (crossvalidation). Na validação cruzada, cada ponto observado é removido e comparado com o predito para aquele local. O RMSPE é a estatística resumo do erro desta superfície de predição. Pode-se tentar diferentes valores de "p" para identificar o que produz o menor RMSPE. Existem dois componentes direcionais que podem afetar as predições na superfície de saída: as tendências globais e as influências direcionais (anisotropia). As tendências globais são, por exemplo, efeitos de ventos, poluição ou água escorrendo morro abaixo, etc. que podem ser retirados do modelo com processos de remoção de tendências (detrending). A anisotropia difere da tendência global em função de que esta última pode ser descrita como 3 Os métodos apresentados nos próximos tópicos foram baseados principalmente em ESRI (2001), um processo físico, e modelada por fórmulas matemáticas. Já a causa da anisotropia não é conhecida, e é modelada como um erro aleatório, e não um processo determinístico que pode ser descrito com uma equação matemática. Ela pode ser tratada com a krigagem. O IDW é um método interpolador que é exato. Poucas decisões são tomadas acerca dos parâmetros do modelo. Este método pode ser adequado para uma visualização ou interpretação preliminar da interpolação de uma superfície. Entretanto, não é realizada uma avaliação da predição de erros, que pode produzir um efeito "bullseyes" ao redor da localização do dado, pequenas áreas que se diferenciam da suavização geral da variável. Este método assume que a superfície possui uma variação local, e funciona melhor se os pontos amostrais estão igualmente distribuídos pela área, sem estarem concentrados em determinado local. Os parâmetros mais importantes a se detectar, então, são as especificações de vizinhança, o parâmetro de poder (power) "p" e o fator de anisotropia, se existir.

Lamas (1994,p.6) assinala três dos principais componentes de um sistema de classificação geodemográfico: - Uma infraestrutura de unidades geográficas suficientemente pequenas, como os setores censitários; - Uma base de dados de informação estatística sobre estas unidades geográficas, em geral o Censo ou outra fonte adicional; e - A criação de um sistema de grupos de unidades geográficas resultante de uma Análise de Cluster, que se trata de agrupar as unidades espaciais que sejam mais próximas entre si e diferenciá-las de outras menos similares. Como normalmente o conjunto de variáveis é muito numeroso e com certo grau de correlação entre si, pode-se reduzir seu número por meio da aplicação de uma Análise de Componentes Principais ou outra técnica estatística de síntese similar, antes de fazer a Análise de Clusters.

Outro objetivo deste paper é o mapeamento e a análise da distribuição socioespacial dos aglomerados subnormais em Goiânia.Para tanto são utilizados dados da Contagem Populacional 
de 2010, foram levantados apenas dados referentes a caracterização sobre segregação socioespacial, como a situação de domicílio no setor, município de residência, domićlíios com identificação de logradouros em Goiânia, dentre outros, especificamente:

a) domicílios particulares permanentes do tipo casa;

b) domicílios particulares permanentes do tipo casa de vila ou em condomínio

c) domicílios particulares permanentes do tipo apartamento

d) domicílios particulares permanentes próprios e quitados

e) domicílios particulares permanentes próprios em aquisição

f) domicílios particulares permanentes alugados

g) domicílios particulares permanentes com abastecimento de água da rede geral

h) domicílios particulares permanentes com banheiro de uso exclusivo dos moradores ou sanitário e esgotamento sanitário via rede geral de esgoto ou pluvial

i) domicílios particulares permanentes com lixo coletado

j) domicílios particulares permanentes com energia elétrica de companhia distribuidora e com medidor de uso exclusivo

k) domicílios particulares permanentes - Existe identificação do logradouro

1) domicílios particulares permanentes - Existe iluminação pública

m) domicílios particulares permanentes - Existe pavimentação

n) domicílios particulares permanentes - Existe calçada

o) domicílios particulares permanentes - Existe meio-fio/guia

p) domicílios particulares permanentes - Existe bueiro/boca-delobo

q) domicílios particulares permanentes - Existe rampa para cadeirante

r) domicílios particulares permanentes - Existe arborização

s) domicílios particulares permanentes - Não existe esgoto a céu aberto

t) domicílios particulares permanentes - Não existe lixo acumulado nos logradouros

Diante do exposto, os mapas e aplicações estão nas análises e resultados. Desse modo, a análise das características dos setores censitários está restrita a estas variáveis.Pesquisas Cadernos do Leste 
bibliográficas sobres os assuntos propostos, os mapeamentos possíveis para a visualização em mapas contribuírampara a consolidação do trabalho, e também com as imensuráveis informações da bolsista do Laboratório LESTE, Bárbara Henriques, que foi de fundamental relevância para a concretização deste paper.

\section{8- RESULTADOS E DISCUSSÕES}

Os fenômenos que ocorrem no espaço e sua compreensão inerente aos aspectos socioespaciais,podem ser observados em uma análise espacial. Neste estudo, os dados estão associados as áreas com contagem e taxas agregadas, definidas por critérios operacionais (dados censitários). Assim, com o propósito de interpretar e inferir as razões que determinam os fatos.

Para a interpretação dos dados espaciais foram gerados mapas coropléticos destacando regiões com altos e baixos valores correspondentes as variáveis aplicadas.

A priori foram gerados mapas em plataforma GIS, estimando o percentual de domicílios alugados, determinando assim, os conjuntos de residências com locatário. Neste sentido a organização espacial pode ser observado na figura 1. 


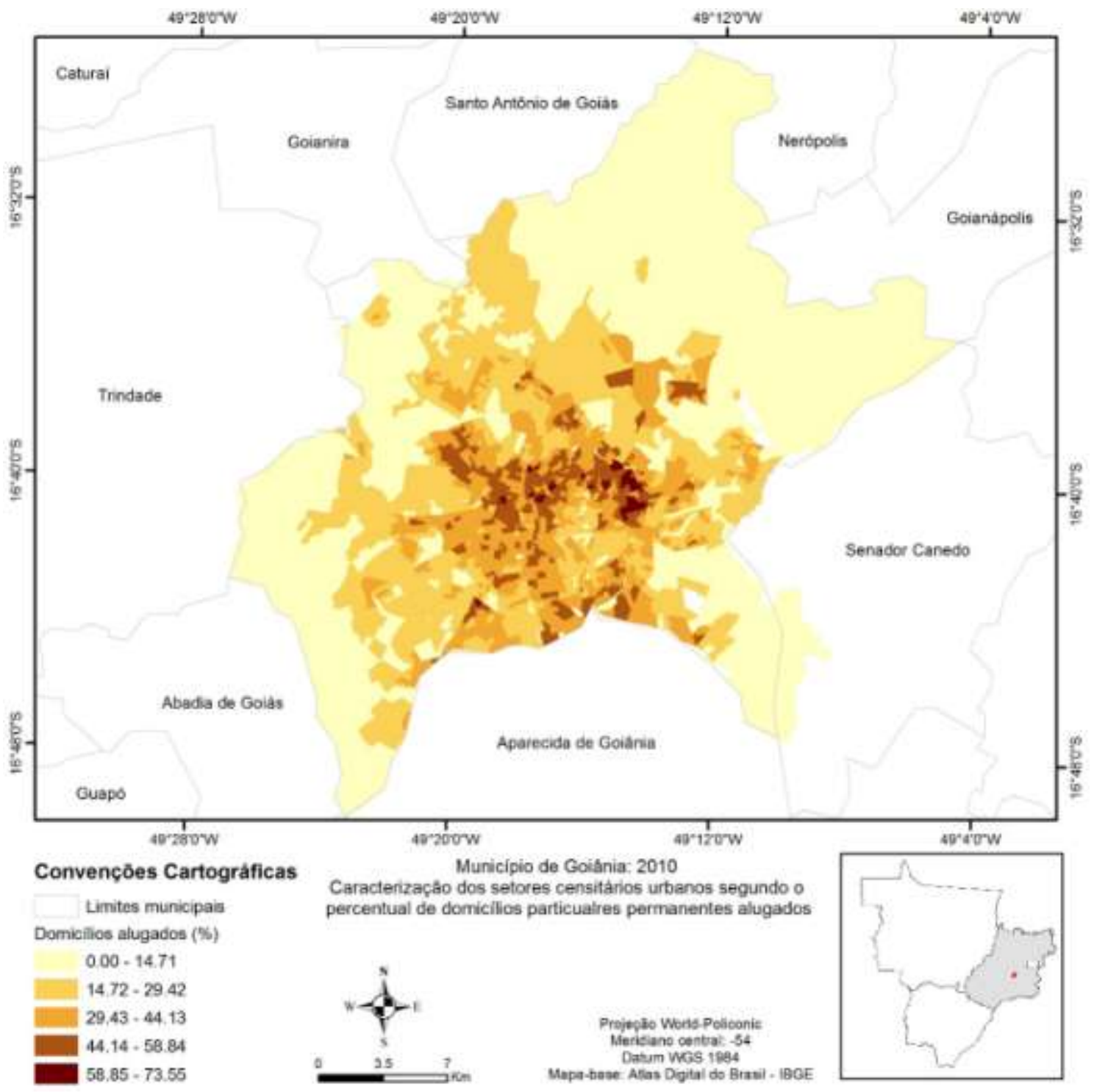

Figura 1. Analise espacial - Percentual de Domicílios alugados

Observa-se que até $14 \%$ dos domicílios alugados pertencem as regiões onde existe poucas habitaçõesem relação a malha urbana do município de Goiânia. A partir dos 58\% a 73\%, mais da metade dos clusters em análise, percebe-se um conjunto de áreas nas proximidades do grande centro da capital. Podemos inferir que como a região central é uma zona histórica e antiga, muitas residências são passadas entre famílias por gerações. Outro fator interessante é a relação de grandes quantidades de comércio presente no bairro popular. Para uma interpretação mais profunda, foi gerado o Índice de Moran que calcula a dependência espacial, que pode ser entendida como a tendência de um valor relacionado a uma variável e associado àsua localização tendo como maior semelhança o valor de amostra de seu vizinho do que ao restante do conjunto amostral. (CÂMARA et al, 2002). 
$\mathrm{Na}$ representação espacial, essa função (Índice de Moran) resulta na tipologia de padrões, onde podemos observar agrupamento de valores altos e próximos (Alta - Alta), baixos e próximos (Baixo - Baixo), outlier de valores altos que não se agrupam, pois se encontram em meio a valores baixos (Alta - Baixa), outlier de valores baixos que não se agrupam, pois se encontram em meio a valores altos (Baixa - Alta) e não significativos, onde, não se enquadram nos agrupamentos, pois apresentam níveis variados assim como os valores dos vizinhos.Esses agrupamentos são geradosponderando a dispersão de Moran, LISA, P-value, Z-score e outros fatores.Logo criou-se, o mapa de autocorrelação caracterizado pelo Indicie de Moran (LISA) em relação aos domicílios alugados. Figura 2.

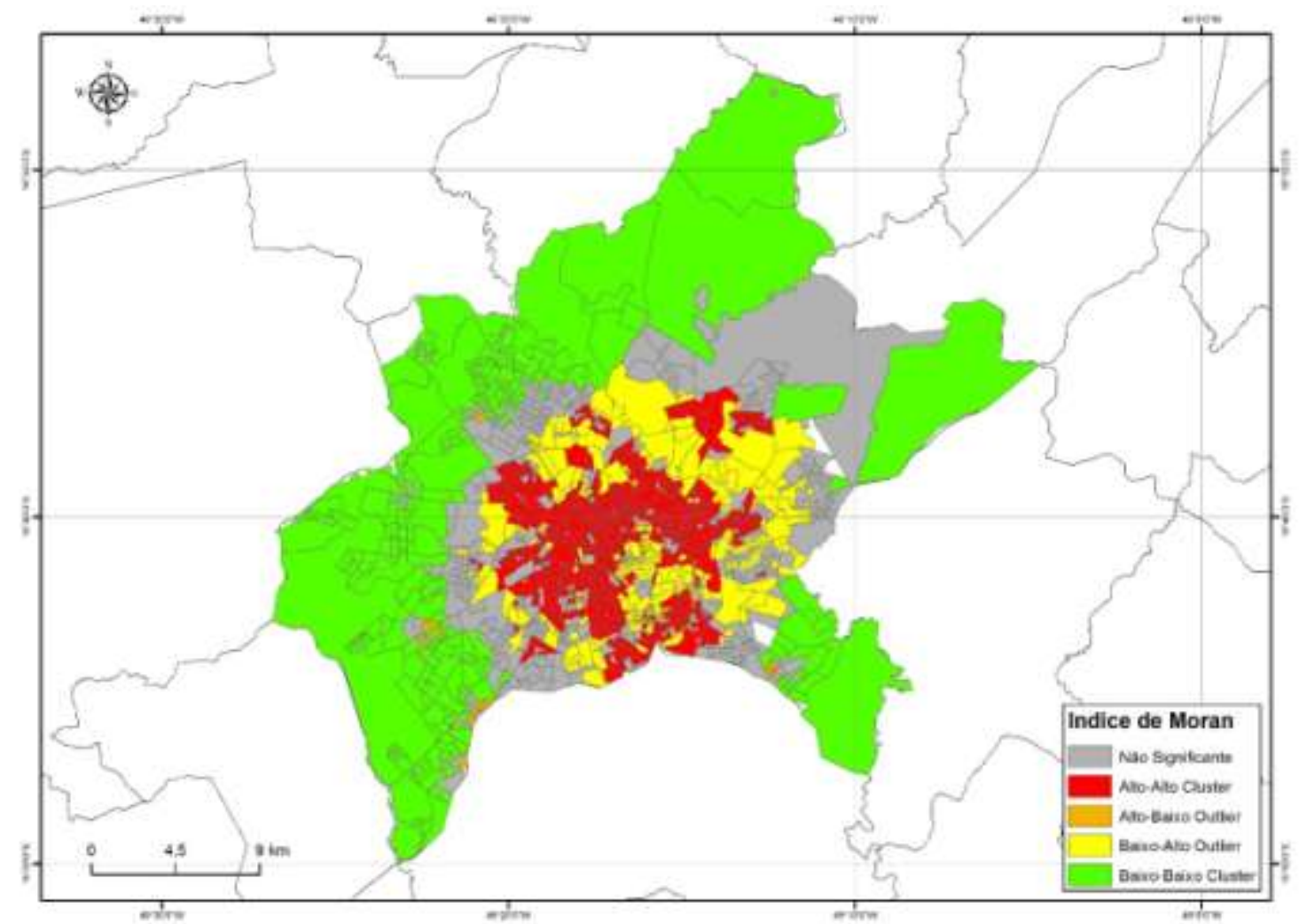

Figura 2. Autocorrelação - Índice de Moran, domicílios alugados

As técnicas utilizadas para caracterização do Índice de Moran estão definidas seguindo as seguintes ordens:

- Especificação do conceito de como a relação espacial ocorre

- O método de como as distâncias serão realizadas a partir de seus vizinhos

A relação espacial é baseada no inverso da distância, que calcula o valor a partir dos valores próximos, utilizando parâmetros para determinar os pesos de cada valor sendo uma 
média ponderada. Ou seja, dependência espacial, quanto mais próximo estiver um valor do outro, maior deverá ser a correlação entre seus valores.

O método de qual tipo de distância será realizada está fundamentado na distância euclidiana, que corresponde a métrica entre dois pontos em linha reta.

Ao observar a figura 2, que a região central do município (em amarelo), bem como o início da região sul de Goiânia, demonstra outliers, valores baixos que não se agrupam, pois, existem valores altos. Porém em sua vizinhança, as regiões do entorno central e meridional da capital apresentam valores altos e próximos um aos outros, caracterizando uma maior porcentagem em domicílios alugados.

\section{9- RENDA}

Os fatores que explicam determinadas situações, em um sentido social, que neste trabalho é a segregação, não está simplesmente detectado em uma ou duas variáveis, mas sim em um conjunto de fenômenos que culminam na marginalização de grupos sociais. Logo, podemos ter uma atenção maior em variáveis que representam a atual circunstância do sistema que tem como objetivo o capital. Para isso, destacamos o parâmetro "renda" para a análise espacial relacionado ao nível de classe pertencente a dinâmica econômica em sociedade.

$\mathrm{Na}$ figura 3, observa-se a disposição entre valores relacionados a renda, onde, proporciona o nível social dos indivíduos por setores censitários. 


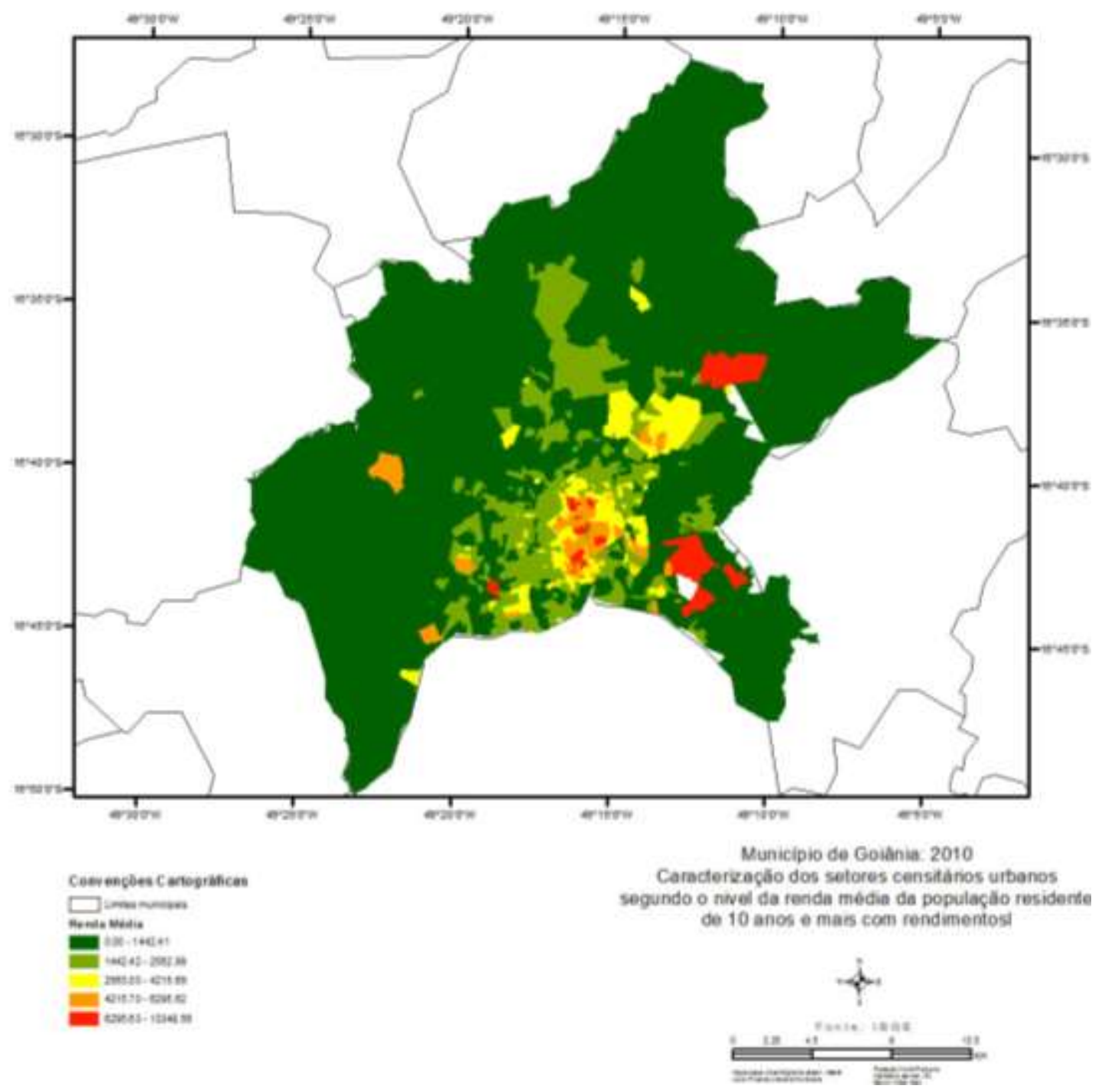

Figura 3. Renda média da população

Neste mapa coroplético, é perceptível a diferença entre rendas da capital, destacado em vermelho, o nível econômico mais elevado. Percebe-se um número maior de setores censitários com renda de até 2500 reais. Um poder econômico baixo em relação a atual conjuntura social. É interessante observar que essa disposição de regiões por renda destaca os grandes condomínios de alto padrão em Goiânia e também bairros de classe média alta como o setor Marista, Bueno,Oeste, JardimGoiás, Setor Alto da Glória, Parque das Laranjeiras, setor Nova Suíça, Setor Bela Vista, Setor Sul, parte do Setor Goiânia 2, setor Jaó, Setor Leste Universitário, Jardins Milão, J. Paris e J. Atenas, Portal do Sol I, Portal do Sol II, Alphaville Flamboyant I e II.

No mapa 4 podemos ver a autocorrelação a partir do Índice de Moran aplicado nessa variável (Renda). 


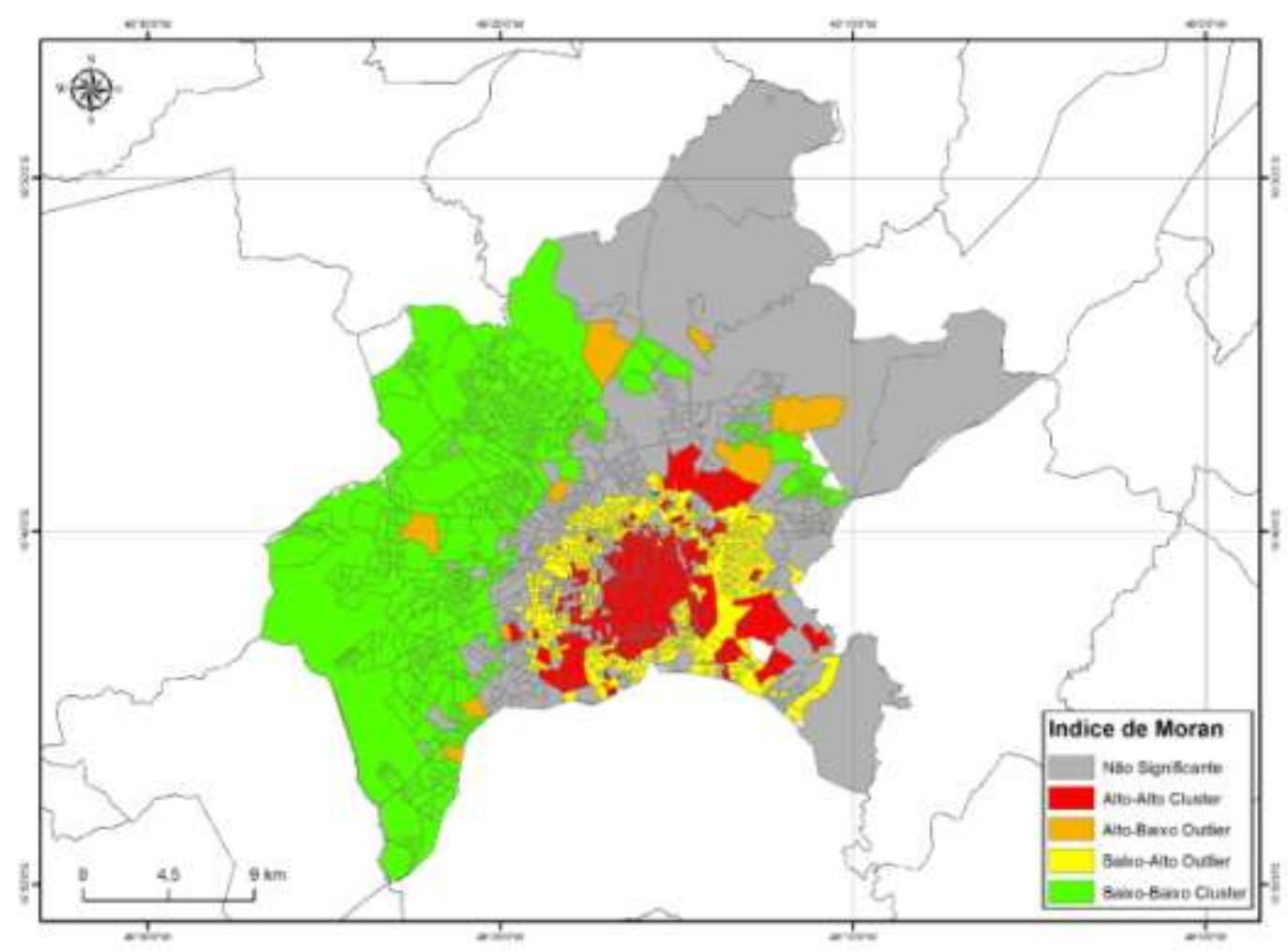

Figura 4. AutcorrelaçãoIndice de Moran - Variável Renda

Aqui percebemos os conjuntos correlacionados estimando as áreas centrais e porção sul de Goiânia com altos e próximos (Alto - Alto) em relação a renda. Interessante perceber que um dos condomínios (Aldeia do Vale) que possui indivíduos com maiores rendas da capital aparece de forma não agrupada (outliers) pois apresenta uma correlação variada, pois, em sua proximidade, está na região periférica do município com alto nível de baixa renda,como por exemplo setor Vale dos Sonhos e Jardim Guanabara.

\section{0- CONCLUSÃO}

O paper ilustra várias desigualdades na capital Goianiense. Percebe- se o reflexo nos indicadores tanto de renda, quanto os expostos na metodologia. A Geoestatística é relevante na quantificação e espacialização dos fenômenos com o processo crescente da urbanização. Goiânia apresenta, uma série de elementos ao mesmo tempo ímpares e plurais, com relação ao lugar de moradia/lazer/gostos/discrepâncias/contradições/usos do capital. $\mathrm{Na}$ parte visual durante algumas pesquisas de campo, foi nítido o contraste entre os casebres, carentes de estrutura e erguidos à deriva, contrastando- se com os condomínios verticais, imponentes, e visto por muitos, inclusive moradores, como símbolos do progresso. Em pesquisas anteriores, há queixas dos bairros menos desfavorecidos economicamente, com relação à segurança, ao transporte Cadernos do Leste 
público, aos postos de saúde e também as escolas. No setor Negrão de Lima, por exemplo, próximo ao centro, foi alvo das territorialidades da mídia e das incorporadoras devido a um forte processo de reurbanização. Este setor hoje é bastante valorizado.

O setor faz divisa com vários bairros da capital. Alguns deles de considerável importância para a economia regional. No entanto, o bairro de maior influência no Negrão de Lima, no âmbito deste trabalho, é a Vila Viana:

“A Vila Viana está localizada às margens da antiga estrada de Ferro que cortava Goiânia. Localizada diretamente à direita do Negrão de Lima e pela pouca estrutura urbana criada, esse setor já foi a ocupação de uma das favelas de Goiânia: A Favela Trilho. Por esse motivo ainda se configura o estilo de ocupação irregular e altos índices de violência". http://www.skyscrapercity.com/showthread.php)

Além disso, o local de onde foram removidos os moradores para Guapó, a vegetação cobriu o local e tem sido utilizado como depósito de animais mortos. Em consequência do lixo que é jogado no local, pudemos observar que estes destroços vêm trazendo risco de várias doenças. Há acúmulo e aumento de roedores, além de pneus velhos que são deixados no local trazendo risco de dengue para todos. Os moradores fizeram várias reclamações junto aos órgãos competentes, porém até agora as devidas providências que foram tomadas tem sido aquém de que os moradores precisam.

Quanto à dimensão geográfica, a concentração de pobres num determinado espaço geográfico é um dos fatores impeditivos de saída da condição de pobreza e de exclusão. Nesse sentido, o confinamento espacial reproduz o isolamento social, perpetuando o círculo vicioso da pobreza. Nessa formulação, há um resgate dos princípios ecológicos da segregação social urbana, mesmo que fatores estruturais estejam no centro da explicação da emergência da subclasse urbana. Por fim, convém chamar a atenção para a dimensão temporal presente na conceituação da nova pobreza urbana. A especificidade da nova pobreza na sociedade pós- fordista é marcada pelo seu caráter irreversível e crônico; é a ausência de expectativas de inserção ou ascensão social que marcam a dinâmica social e urbana no modelo econômico anterior. Outra perspectiva analítica tem abordado a relação entre reestruturação econômica e mudanças espaciais, privilegiando o papel do capital imobiliário no atual quadro de supremacia do setor financeiro.

A emergência de um novo padrão de segregação urbana é analisada não mais sob a perspectiva das transformações na estrutura sócio ocupacional, e sim a partir da lógica de atuação da atividade de construção civil e mercantilização. Neste sentido vê- se a necessidade e relevância 
de estudos com essa temática, diante da diversidade de implicações na produção e reprodução do espaço geográfico.

\section{REFERÊNCIAS BIBLIOGRÁFICAS}

ALMEIDA, Maria Geralda. A Geografia imaginária dos lugares turísticos. Disponível em http://www.geo.ufv.br/simposio/simposio/trabalhos/comunicacao_coordenada/008.pdf, 2008.

ARRAIS, Cristiano Pereira Alencar. Identidade e cidades de fronteira, um estudo sobre a construção de Goiânia a partir do conceito de momento de fronteira. Goiânia: UFG. 2003. (dissertação de mestrado).

CÂMArA, G. CARvalho, M, S. CRUZ, O, G. CORREIA, V. Análise espacial de áreas. 2002.

CHAVEIRO, Eguimar Felício. Et all(org). Geografia e Cultura os lugares da vida e a vida dos lugares. Goiânia. Vieira, 2008.

INSTITUTO BRASILEIRO DE GEOGRAFIA E ESTATÍSTICA. Censo Demográfico Aglomerados Subnormais Primeiros Resultados. Rio de Janeiro, 2011. http://www.ibge.gov.br/home/dowload/ Acessado em:

nov. De 2010.

JACOB; Alberto Augusto Eichman; YOUNG, Andrea Ferraz. O uso de métodos de interpolação espacial de dados nas análises sociodemográficas. Disponível em http://www.abep.nepo.unicamp.br/encontro2006/docspdf/ABEP2006_388.pdf

HAESBAERT, Rogério. O mito da desterritorialização: do "Fim dos territórios" à multiterritorialidade. Rio de Janeiro: Bertrand Brasil, 2004. 395p.

LEFÈBVRE, Henri. A revolução urbana. Tradução de Sergio Martins. Belo Horizonte: Editora UFMG, 1999a O Direito à Cidade. $5^{\circ}$ Edição, 2009.

MACHADO, L.A. Uma cidade no sertão. In: Filho, M. F. L.; (Org.). Formas e tempos de cidade. Goiânia: Cânone; Ed. UCG, 2007. 49-88 p.

MARICATO, Ermínia. A TERRA É UM NÓ NA SOCIEDADE BRASILEIRA.Também Nas Cidades. Disponível em: http://www.usp.br/fau/depprojeto/labhab/biblioteca/textos/maricato_terranosociedadebrasilei ra.pdf.2007

MARTINS, José de Souza. Capitalismo e Tradicionalismo. Ed. Pioneira. São Paulo, 1975.

OLIVEIRA, Eliezer Cardoso de. Imagens e mudança cultural em Goiânia. Dissertação de Mestrado UFG. 2003. 
PELA, Márcia Cristina Hizim. Uma nova (des)ordem nas cidades: o movimento dos sujeitos não desejados na ocupação dos espaços urbanos das capitais do cerrado -G oiânia, Brasília e Palmas. Tese de doutorado defendida na UNIVERSIDADE FEDERAL DE GOIÁS, Instituto de Estudos Socioambientais Programa de Pós-Graduação em Geografia, 2014.

PESAVENTO, Sandra Jatahy Cidades visíveis, cidades sensíveis, cidades imaginárias. Revista Brasileira de História, 2007, vol.27, n. 53

RAFFESTIN, C. Por uma Geografia do poder. São Paulo: Ática, 1993.

SANTOS, Elizete de Oliveira. Segregação ou fragmentação socioespacial? Novos padrões de estruturação das metrópoles latino-americanas. GeoTextos, vol. 9, n. 1, jul. 2013.p. 41-70

SILVA, Luiz Sérgio Duarte da. A Construção de Brasília: modernidade e periferia. Goiânia: Ed. Da UFG, 1997.

SOARES, Rodrigo Oliveira. Goiânia: morar na cidade entre o ato e o concreto. V Simpósio Internacional de História e Identidades. UFG, 2011.

TEIXEIRA, Elisabeth. As três metodologias: Acadêmica, da Ciência e da Pesquisa. Belém: UFPA, 2001.

VILLAÇA, F. Espaço intra- urbano no Brasil. São Paulo: Studio Nobel, Fapesp, 1998. 